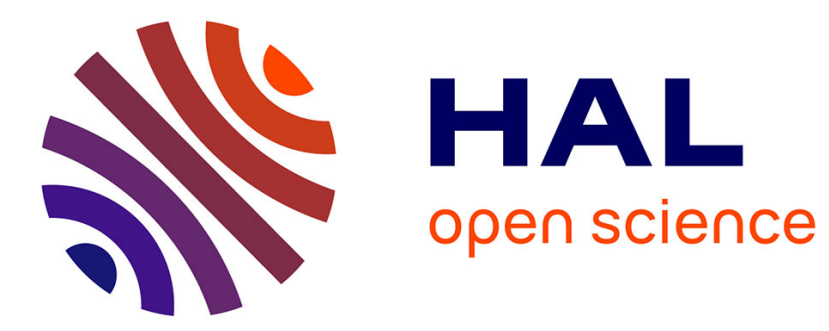

\title{
Experiment and simulation of the dry particle coating
} Akira Sato, Eric Serris, Philippe Grosseau, Gérard Thomas, Alain Chamayou, Laurence Galet, Michel Baron

\section{To cite this version:}

Akira Sato, Eric Serris, Philippe Grosseau, Gérard Thomas, Alain Chamayou, et al.. Experiment and simulation of the dry particle coating. 5th International Workshop on Granulation. Granulation Conference Lausanne, Zwitzerland, Jun 2011, Lausanne, Switzerland. pp.99. hal-00616515

\section{HAL Id: hal-00616515 https://hal.science/hal-00616515}

Submitted on 22 Aug 2011

HAL is a multi-disciplinary open access archive for the deposit and dissemination of scientific research documents, whether they are published or not. The documents may come from teaching and research institutions in France or abroad, or from public or private research centers.
L'archive ouverte pluridisciplinaire HAL, est destinée au dépôt et à la diffusion de documents scientifiques de niveau recherche, publiés ou non, émanant des établissements d'enseignement et de recherche français ou étrangers, des laboratoires publics ou privés. 


\title{
EXPERIMENT AND SIMULATION OF DRY PARTICLE COATING
}

\author{
Akira Sato $^{1,2}$, Eric Serris ${ }^{1}$, Philippe Grosseau ${ }^{1}$, Gérard Thomas ${ }^{1}$, Alain Chamayou ${ }^{2}$, \\ Laurence Galet ${ }^{2} \&$ Michel Baron ${ }^{2}$
}

1 ENSMSE, LPMG- FRE 3312, 158 cours Fauriel, 42023 Saint-Etienne, France

2 EMAC, Rapsodee, FRE CNRS 3213, université de Toulouse, Campus Jarlard, 81013 Albi, France

Laurence.Galet@mines-albi.fr

\begin{abstract}
The objective of this study is to get a better understanding of dry powder coating process using experiments and numerical method. Materials chosen as host particles are SUGLETS ${ }^{\circledR}$ (spherical granules mainly consisting of sugar) and as invited particles, magnesium stearate (MgSt). These two materials are introduced in the Cyclomix high shear mixer. Operations were performed at various mixing time and rotation speed of the Cyclomix. The surface morphology analysis has confirmed that Suglet particles are coated by MgSt. The product properties such as flowability, wettability and particle size distributions were also characterized. The particle motion in the Cyclomix has been simulated by using Discrete Element Method (DEM). Both number of collisions and the collision force frequency are calculated. The simulation shows an increase of the collision number with the rotational speeds. This result indicates that the higher rotation speed should be better for the dry coating process as long as the particles aren't broken down.
\end{abstract}

\section{KEYWORDS}

Dry particle coating, Discrete Element Method, Cyclomix

\section{INTRODUCTION}

Dry particle coating is a method to modify the properties of powders by attaching the fine particles (invited particles) onto the surface of core particles (host particles) by mechanical forces using neither organic solvent nor aqua binder. Because of its environmental friendliness and simple process, it is getting more and more importance for industries. Even though a lot of experimental works of the dry particle coating are reported in the literature [1-6], the theoretical modelling for such process [7], that is also very important to optimize the process or to design new geometry of the coating apparatus, is found to be less comprehensive. The objective of this study is also to understand the dry powder coating by experimental and numerical methods. Discrete Element Method (DEM), proposed by Cundall and Strack [8], has been applied to simulate the motion of the particles inside the coating apparatus. DEM is one of the most popular techniques for simulating and analysing the solid particle behaviour and has been successfully applied in many fields [9-11]. Then this work describes our research to reveal the effect of operating condition such as rotation speed of the mixer on the particles coating and its numerical approach.

\section{EXPERIMENT}

\subsection{Materials}

For the powder couple, the Suglets and magnesium stearate $(\mathrm{MgSt})$ were chosen as host/invited particles respectively. Suglets were provided by NP pharm company. This powder consists of spherical sugar core composed of mainly sucrose and maize starch. Also it has highly hydrophilic characteristic. This material is mainly used as excipient in capsule and tablet formulation, 
particularly in multiparticulate systems. They form cores upon which API are coated for controlled or sustained release drug delivery technologies. Figure 1 (a) shows a SEM picture of Suglets particles. They are spherical and their surface seems to have crystal-like form. The median particle size of Suglet, $D_{50}$ is about $250 \mu \mathrm{m}$. MgSt were used as invited particles. This material is a fine, white, greasy, cohesive and hydrophobic powder widely used in pharmaceutical formulations as a lubricant. The shape of the magnesium is relatively random, including needle-like and plate-like configuration (Figure 2(b)). The $D_{50}$ is about $4 \mu \mathrm{m}$. These properties of the samples are summarized in Table 1.

Table 1. Properties of suglets and MgSt.

\begin{tabular}{cccc}
\hline particles & $\mathrm{D}_{50}(\mu \mathrm{m})$ & solid density $(\mathrm{kg} / \mathrm{m} 3)$ & water affinity \\
\hline Suglets & 250 & 158.0 & hydrophilic \\
& 4 & 114.0 & hydrophobic \\
\hline
\end{tabular}
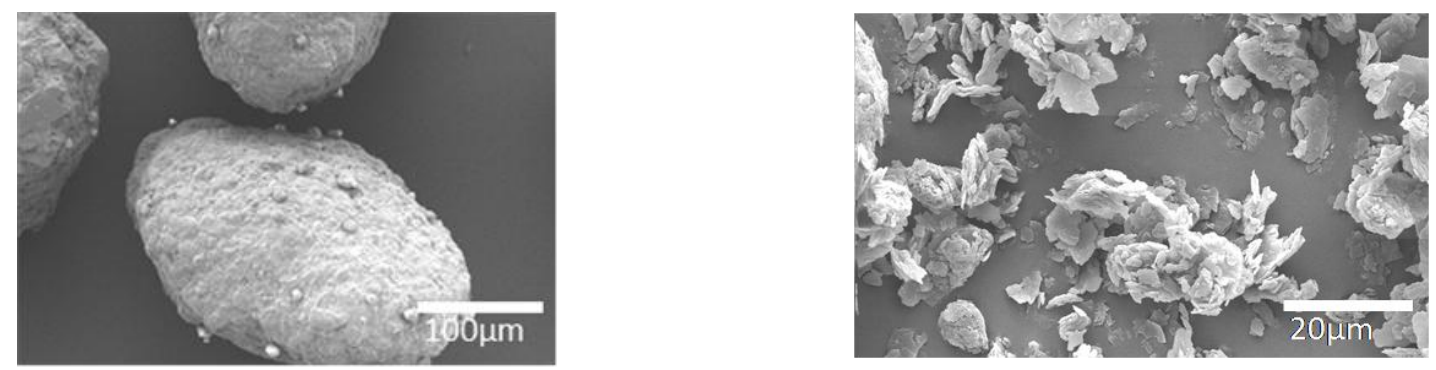

Figure 1. SEM images of Suglets(a) and MgSt(b).

\subsection{Coating process}

A 1L Cyclomix has been chosen to perform a dry coating in this study. This apparatus is defined as a high shear mixer/granulator, manufactured by Hosokawa Micron B.V. As it can be seen from Figure 2, it consists of a conical vessel with an axial impeller in the centre equipped with four sets of special designed blades. It applies high mechanical impact and shearing forces on the particles in order to break the fine agglomerates and coat them on the host particles. This device has also been used successfully for dry particle coating experiment [12]. Assuming the invited and host particles have uniform sizes respectively and spherical shape, the mass ratio of invited to host particles to obtain a $100 \%$ monolayer surface coverage, $w$ could be expressed using the size ratio of host and invited particle, $K_{\mathrm{H}}[13]$ :

$$
\begin{gathered}
w=\frac{4 C_{2 D}\left(k_{H}+1\right)^{2}}{4 C_{2 D}\left(k_{H}+1\right)^{2}+\frac{\rho_{H}}{\rho_{I}} k_{H}^{3}} \\
k_{H}=\frac{\mathrm{R}_{H}}{\mathrm{R}_{I}}
\end{gathered}
$$


Where, $C_{2 \mathrm{D}}$ is the packing fraction of invited particles on the surface of host particle, $\rho_{\mathrm{H}}$ and $\rho_{\mathrm{I}}$ are the densities of host and invited particles, and $R_{\mathrm{H}}$ and $R_{\mathrm{I}}$ are the radii of host and invited particle respectively. Estimating the packing fraction shall be that of compact hexagonal structure: $C_{2 \mathrm{D}}=0.906$, the ideal mass ratio for the $100 \%$ surface coverage is about $3.92 \%$. In this research, the mass ratio has been chosen to be $5 \%$. To focus on the effect of the operation time and rotational speeds, the mass of the host particles and the mass fraction was fixed. The rotational speeds were in the range from 500 to $1500 \mathrm{rpm}$ and operation time was varied from 1 to $30 \mathrm{~min}$. The operation conditions are summarized in Table 2.

Table 2. Operating conditions.

\begin{tabular}{c|ccc}
\hline Coating device & Rotation speed (rpm) & Time (min) & Mass \% of MgSt \\
\hline Cyclomix & $500,1000,1500$ & $1-30$ & $5 \%$ \\
\hline
\end{tabular}

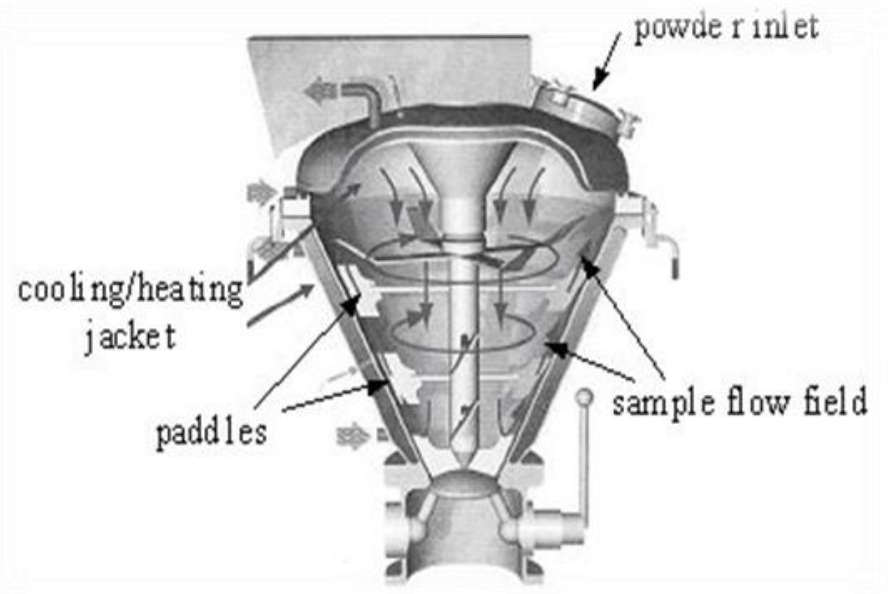

Figure 2. Scheme of the Cyclomix high shear mixer.

\subsection{Characterization}

The various characterization methods were used after dry particle coating. The surface morphology of the particles has been observed by scanning electron microscopy (SEM). The SEM allows us to analyse the surface morphology of the particles and also identify the guest particles on the surface of the host particles. Malvern Mastersizer 2000 laser diffraction granulometer has been used in order to analyse the different size distributions of the particles and also to evaluate qualitatively the interactions between guest and host particles by changing dispersing air pressure. Modification of different surface properties of the particles was analysed using various techniques. Freeman technology powder rheometer (FT-4) has been used in order to characterise the flowability of products. This device analyses the flow rate index (FRI) that represents the flowability of a powder, high values are characteristic of cohesive powders. The sessile drop test has been done to evaluate the wettability of the products.

\section{SIMULATION OF THE PARTICLE MOTION IN CYCLOMIX}

The particle motion in the Cyclomix has been simulated the discrete element method (DEM). Figure 3 shows the geometry of Cyclomix modelled for the DEM simulation. The particles with the 
properties of the host particles given in Table 3 were placed in the vessel of the Cyclomix with hexagonal-close packed structure. Gravity has been introduced settle the assembly. The current computer power is not enough to simulate the actual number of particles. Then smaller number of particles (about 40000), but with larger size $(2.0 \mathrm{~mm})$ has been applied. To estimate the coating efficiency, several values that could be related to the coating has been measured, such as the collision frequency, average rotational distance and the distribution of the collision forces. Especially, the average rotational distance shown in Eq. 2 could be very important for the coating. When the host particle rotates (like in Figure 4), the invited particles near this host particle would be attached like as making a snowman.

$$
\varphi_{\text {avg }}=\frac{\sum_{N}^{i=1} \varphi_{i}}{N}
$$

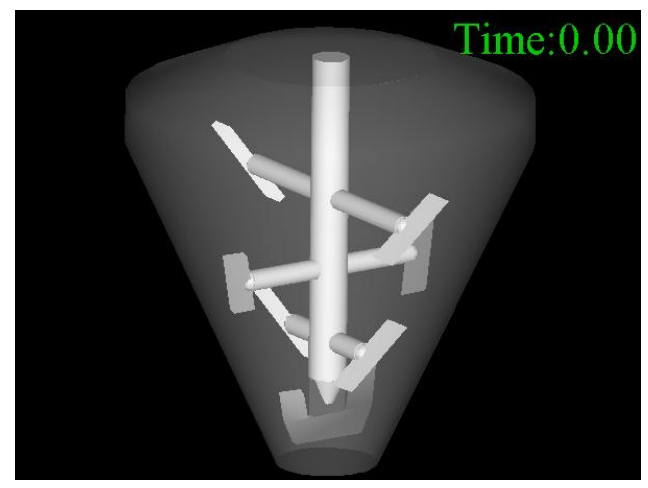

Figure 3. The geometry of the modelled Cyclomix.

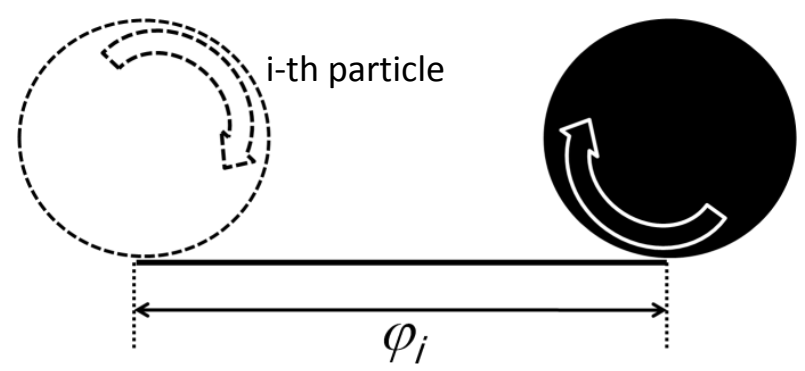

Figure 4. Definition of rotational distance of the i-th particle.

Table 3. Parameters for DEM simulation.

\begin{tabular}{|c|c|c|}
\hline Young's modulus & $\mathrm{E} \quad[\mathrm{GPa}]$ & 4.5 \\
\hline Poisson's ratio & {$[-]$} & 0.30 \\
\hline Density & {$[\mathrm{kg} / \mathrm{m} 3]$} & 160 \\
\hline Coefficient of restitution & {$[-]$} & 0.16 \\
\hline Time step & $\mathrm{t} \quad[\mathrm{sec}]$ & $2.0 \times 10-6$ \\
\hline Total simulation time & $\mathrm{T} \quad[\mathrm{sec}]$ & 1.5 \\
\hline
\end{tabular}




\section{RESULT AND DISCUSION}

\subsection{Surface morphology}

The SEM images of the particle surface after the dry coating operation are shown in Figure 5. At the coated particle at $500 \mathrm{rpm}$ and $1 \mathrm{~min}$ operation, it can be seen that the almost all the surface of the particle is covered by MgSt. It might be because the experiments were carried out with excess of ideal mass ratio, the surface of the host particles was also easily covered by the invited particles. However, after operating much more time, surface is getting smoother. That could be because the $\mathrm{MgSt}$ deforms film-like coating by shear force or impaction, that is to say, dry coating progressed to film coating. As for the coated product at $1000 \mathrm{rpm}$ and $1 \mathrm{~min}$ operation, the surface seems rougher than that of 500rpm operation. After 10 and $30 \mathrm{~min}$ operation, those surfaces seem to present the agglomeration on itself. During the operation, a little flake of host particle could separate from the main part, agglomerated each other, and then finally attached to the surface of the host particles again. Therefore, the surface would be a mixture of the host particle flake and MgSt. At $1 \mathrm{~min}$ and $1500 \mathrm{rpm}$ operation, the surface is seen to be similar to that of $30 \mathrm{~min}$ and $500 \mathrm{rpm}$ operation. After 10 and 30 min operation, they seem to have similar surface of the particle after 10 and 30 min and $1000 \mathrm{rpm}$.

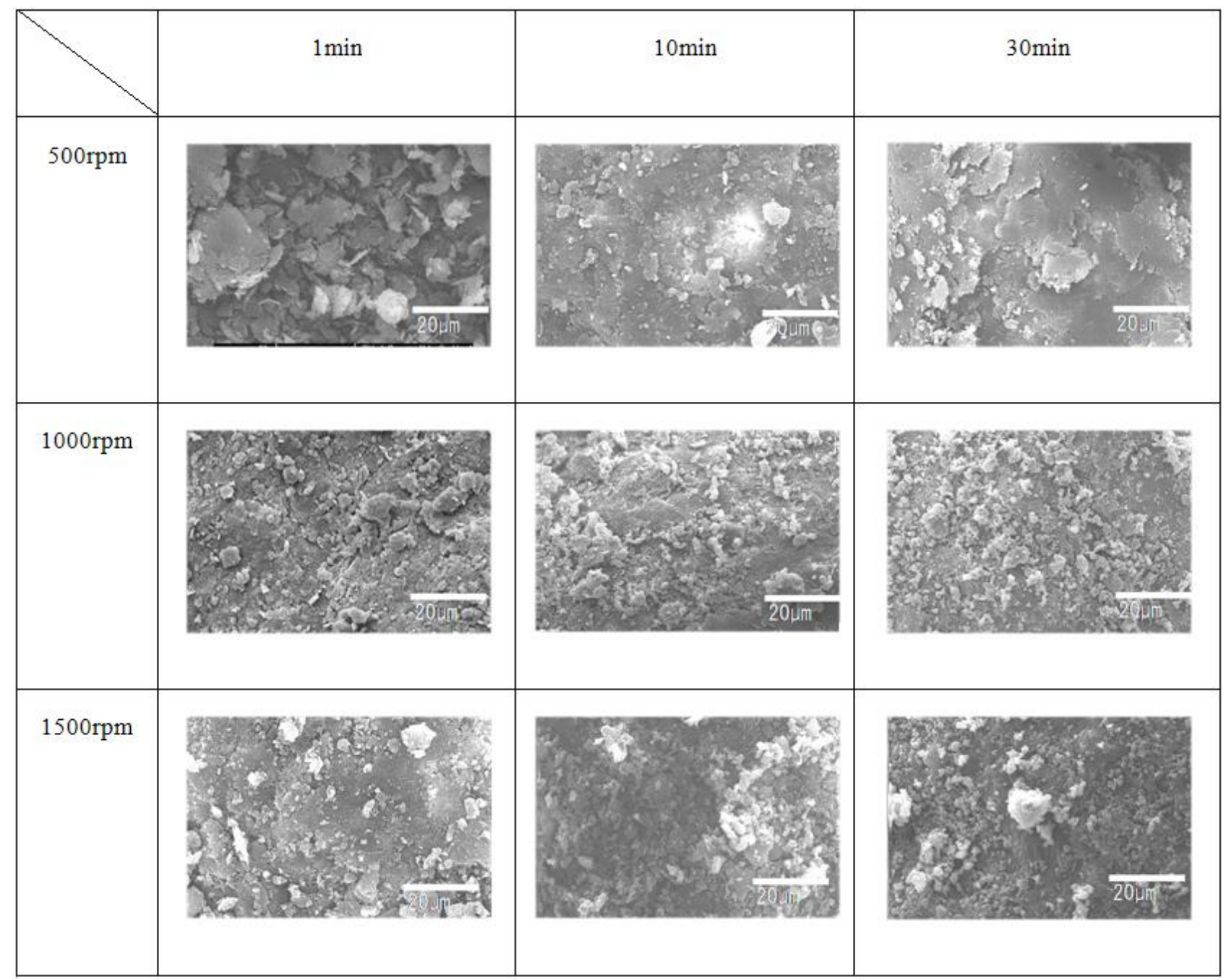

Figure 5. SEM images of particle surface after each operation. 


\subsection{Flowability}

The value of Flow Rate Index (FRI) was measured after the dry coating treatment. Figure 6 shows FRI as a function of operating time at each rotational speed. The initial value of FRI is that of host particle. At $500 \mathrm{rpm}$, FRI decreases with an increase in the operating time. In the other word, the flowability of the composite is getting better. In addition, the surface is getting smoother along with the operation time at $500 \mathrm{rpm}$ as seen in Figure 5. That could help the particles to have better flowability. As for $1000 \mathrm{rpm}$, FRI decreases with an increase in the operation time more rapidly than that of $500 \mathrm{rpm}$ up to $5 \mathrm{~min}$, and then it seems to be stable. At $1500 \mathrm{rpm}$, FRI decreases with an increase in the operation time up to just $1 \mathrm{~min}$, and then it increases rapidly to the certain value. That could be because of the fragmentation or breakage of the host particles happen due to the high shear stress and impaction between particle-particle and particle to the wall/impeller.

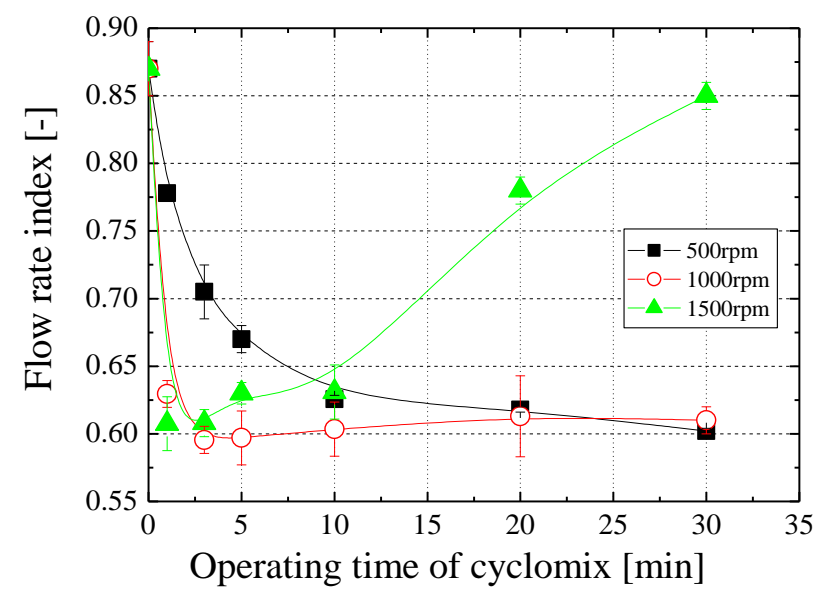

Figure 6. Flow rate index as a function of operating time.

\subsection{Wettability}

The water drop test has been carried out to analyse the wettability of the products. Figure 7 shows that the images of the water drop test for raw Suglets and for the product submitted to a 1 min at $1000 \mathrm{rpm}$ treatment. As can be seen, the water drop has been absorbed as soon as it dropped on the powder bed of the raw Suglets due to its high hydrophilic property. On the other hand, the water drop on the product remains even after $30 \mathrm{~s}$. It could be said that as for the wettability, the 1 min operation at $1000 \mathrm{rpm}$ is enough to change the surface property from hydrophilic to hydrophobic. Figure 8 shows the contact angle of the products $30 \mathrm{~s}$ after the water drop on the surface. The initial point of this figure is calculated and induced identically by the following equations.

$$
\theta\left(t_{0}\right)=S_{H 0} \theta_{H}+\left(1-S_{H 0}\right) \theta_{I}
$$

$$
S_{H}=\frac{k_{H}{ }^{2}}{4 C_{2 D}\left(k_{H}+1\right)^{2}+{k_{H}}^{2}}
$$

Where, $\theta_{\mathrm{H}}$ and $\theta_{\mathrm{I}}$ are contact angles of host and invited particle respectively, and $S_{\mathrm{H}}$ is surface fraction of host particles. As can be seen in Figure 8, at $500 \mathrm{rpm}$ the contact angle increase with an 
increase of operation time until $5 \mathrm{~min}$ and then, it seems to become stable and the value is almost as same as that of MgSt, which indicates that the surface of the host particle is almost covered by the $\mathrm{MgSt}$ at $5 \mathrm{~min}$ operation. At $1000 \mathrm{rpm}$, the contact angle increases more rapidly than that of 500 rpm until 1 min operation, however, the contact angle decreases slightly along with the operation time after that. That might be because of the fragmentation or the breakage of the host particles. At $1500 \mathrm{rpm}$, it also increases until $1 \mathrm{~min}$ operation, then, after that, it starts to decrease along with the operation time with more remarkable rapidity. That also might be due to the breakage of the host particles.

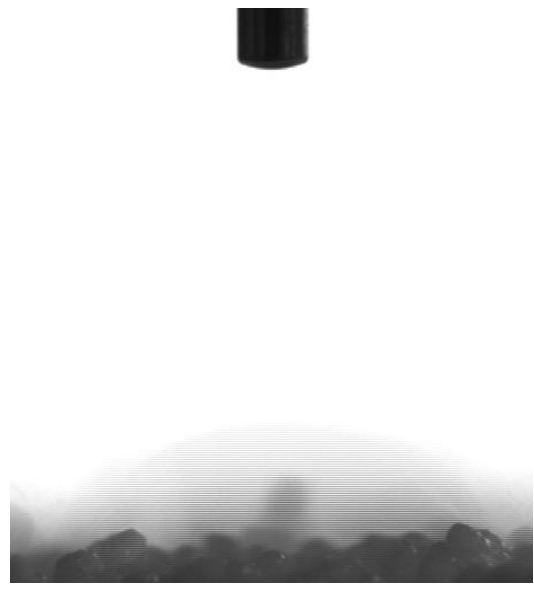

(a)

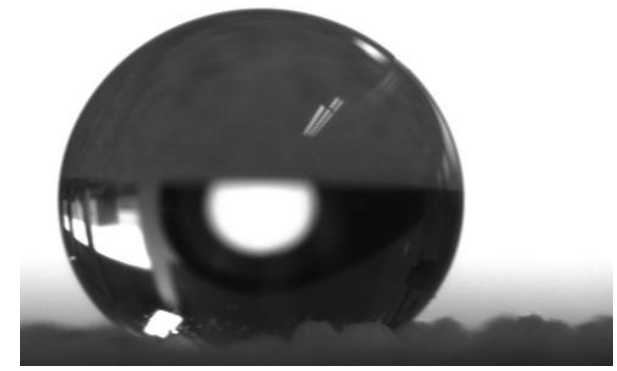

(b)

Figure 7. The images of the water drop test : (a) Raw suglets, (b) Sulget $+5 \%$ MgSt 1 min at 1000rpm.

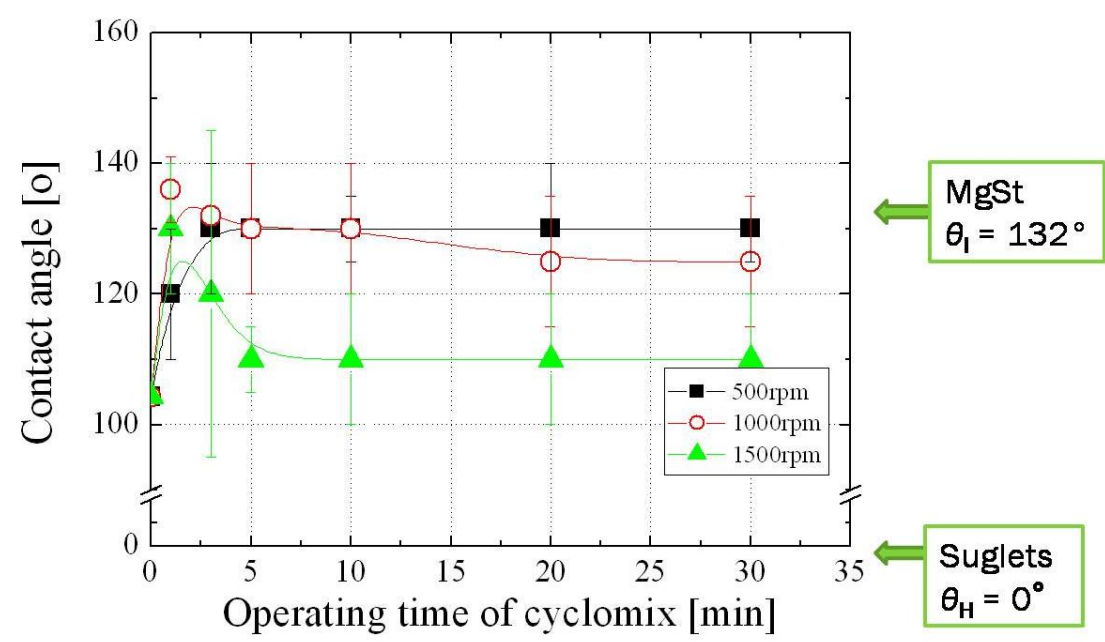

Figure 8. Contact angles as a function of operation time.

\subsection{Particle size distribution analysis}

Figure 9 shows the number distribution obtained by a Malvern Mastersizer dry feed system with $0.5 \mathrm{bar}$ air pressure. All of the peaks are around $250 \mu \mathrm{m}$ that is near to the median diameter of the Suglets. Figure 10 shows the volume distribution obtained with 0.5 bar. Almost all the peaks are around $250 \mu \mathrm{m}$, however, there is one difference observed. The peaks of the samples corresponding to $1 \mathrm{~min}$ and $3 \mathrm{~min}$ at $500 \mathrm{rpm}$ operations are smaller than those observed at the other samples. It can be estimated that the very small particles are measured in these samples, that is to say, there are 
already separated MgSt or fragment of the Suglets in the sample. Figure 11 shows the volume distribution obtained with 2.5 bar air pressure. At $500 \mathrm{rpm}$ there are small peaks around 7-8 $\mu \mathrm{m}$. From their sizes, it could be estimated that these peaks are that of magnesium stearate separated due to the air pressure. At $1000 \mathrm{rpm}$, on the other hand, there is no remarkable change observed. At $1500 \mathrm{rpm}$, there also can be seen smaller peaks around $60 \mu \mathrm{m}$. These peaks might be the broken or abraded Suglets. The number distribution would show these tendencies clearer. Figure 12 shows the number distributions obtained with 2.5 bar air pressure. At $500 \mathrm{rpm}$, majority of the peaks is around $250 \mu \mathrm{m}$ that is almost as same as that of Suglets itself. However, for the products obtained after $1 \mathrm{~min}$ and $3 \mathrm{~min}$ operations, there is smaller peak, which is around 7-8 $\mu \mathrm{m}$. That could be estimated that it is MgSt separated during the analysis under pressure of 2.5 bar. At $1000 \mathrm{rpm}$, the majority of the peak remains around the $50 \%$ particle size of Suglets. Only the particles after 1 min operation has smaller peak, which is similar to that of $500 \mathrm{rpm}$. That tendency indicates that $1000 \mathrm{rpm}$ operation gives stronger adhesion between host and invited particles than that of $500 \mathrm{rpm}$. At 1500 $\mathrm{rpm}$, a different tendency was observed. There are the peaks around $60 \mu \mathrm{m}$, which couldn't be seen at the others rotation speed. Hence, they should be the consequence of breakage or abrasion.

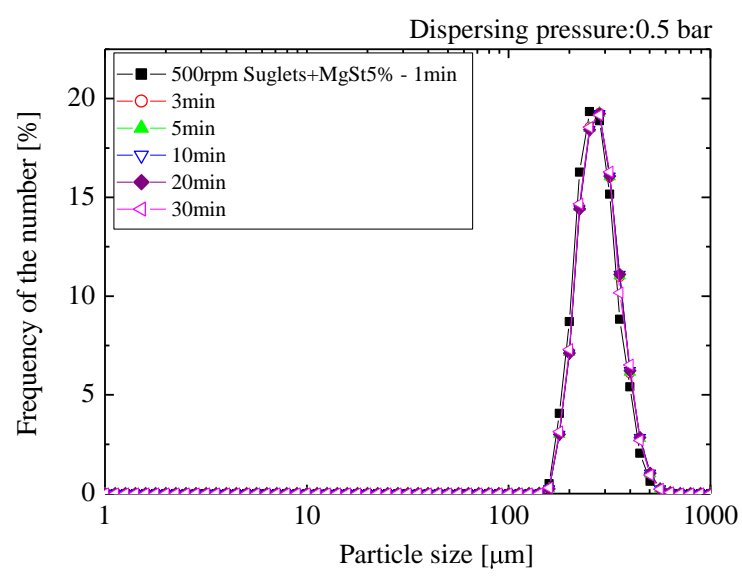

(a)

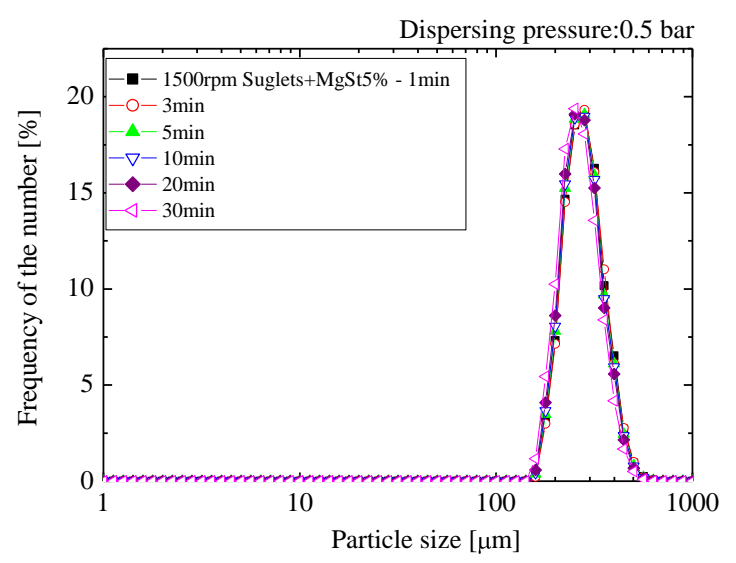

(c)

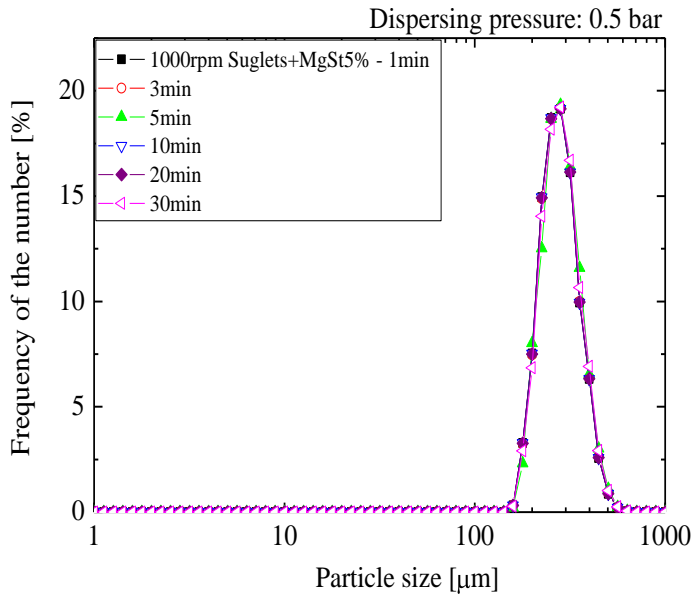

(b)

Figure 9. Number distribution of the particles after operation using dispersion pressure of 0.5 bar: (a) $500 \mathrm{rpm}$, (b) 1000 rpm, (c) $1500 \mathrm{rpm}$. 


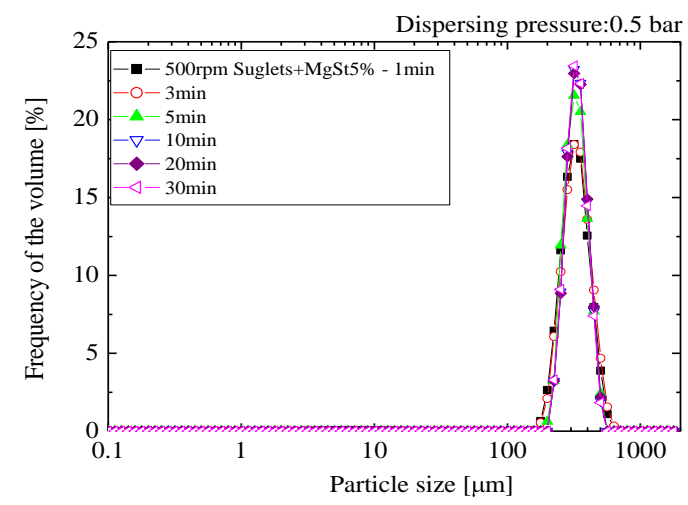

(a)

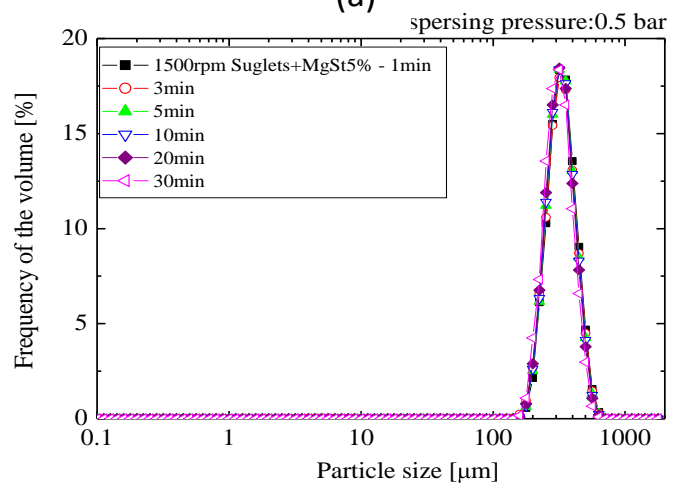

(c)

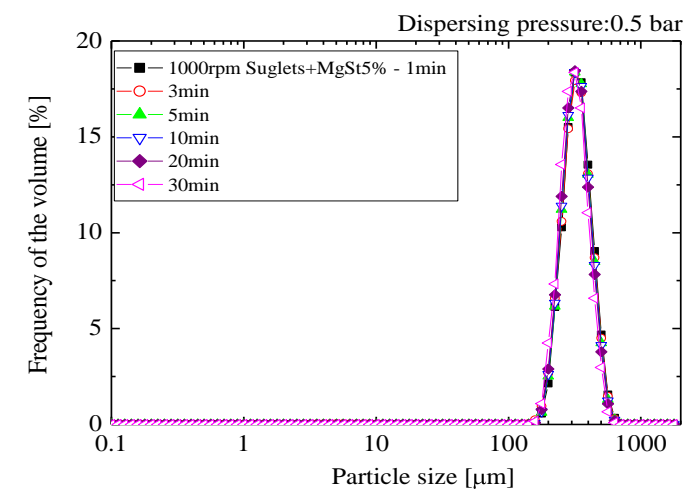

(b)

Figure 10. Volume distribution of the particles after operation using dispersion pressure of 0.5 bar: (a) $500 \mathrm{rpm}$, (b) $1000 \mathrm{rpm}$, (c) $1500 \mathrm{rpm}$.

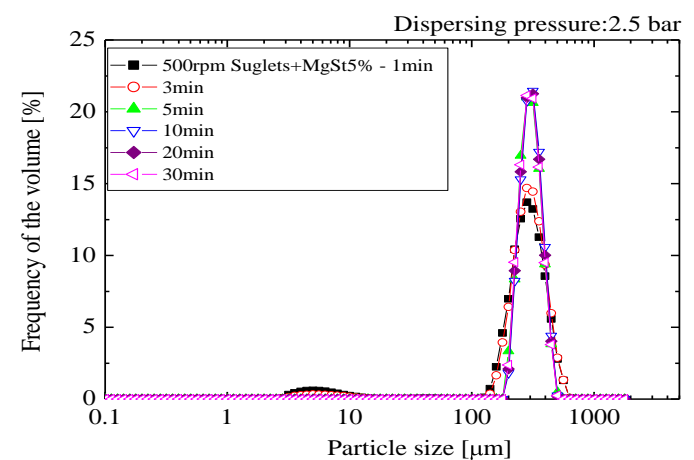

(a)

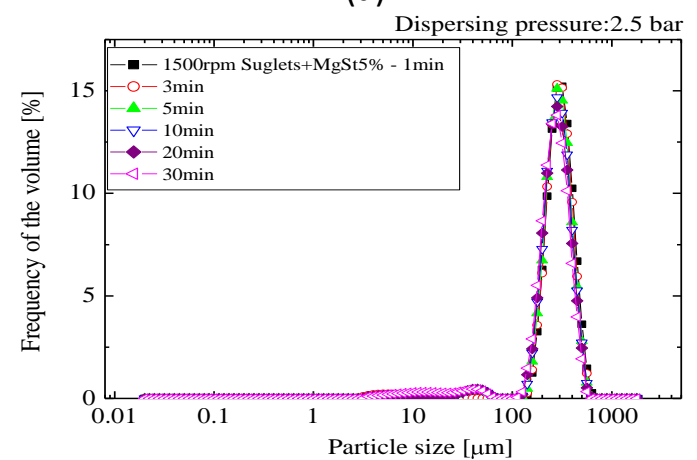

(c)

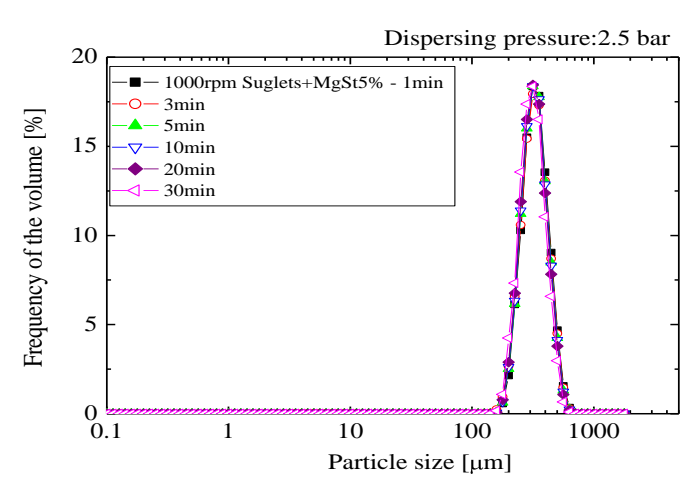

(b)

Figure 11. Volume distribution of the particles after operation using dispersion pressure of 2.5 bar: (a) $500 \mathrm{rpm}$, (b) $1000 \mathrm{rpm}$, (c) $1500 \mathrm{rpm}$. 


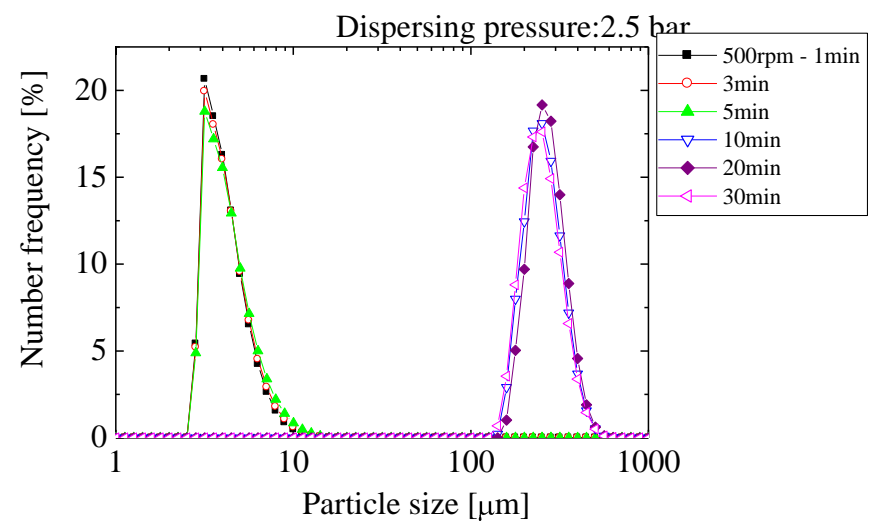

(a)

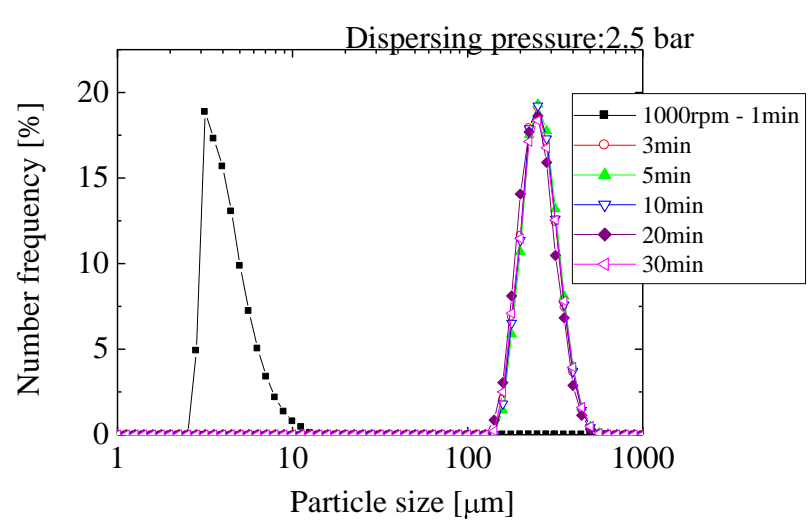

(b)

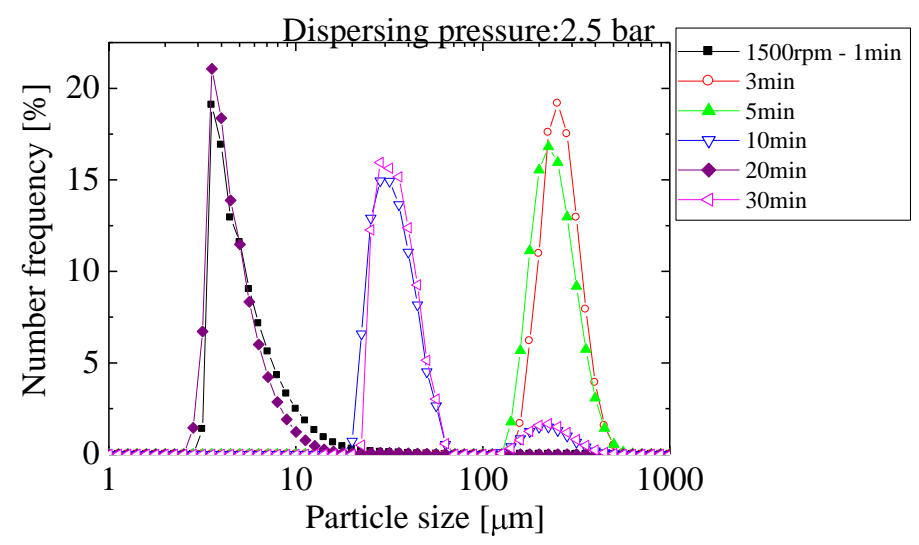

(c)

Figure 12. Number distribution of the particles after operation using dispersion pressure of 2.5 bar: (a) $500 \mathrm{rpm}$, (b) $1000 \mathrm{rpm},(\mathrm{c}) 1500 \mathrm{rpm}$.

\subsection{Numerical result}

An example snapshot of DEM simulation is shown in Figure 13. The colour shows the velocity distribution of the particles, blue particles have lower velocity and red one has higher velocity. The particles around the impeller have high velocity. There are few particles at the bottom part of the vessel, which indicates that impellers force the particles to the wall and then, due to the effect of the conical shape wall, the particles go to the upper side of the vessel. Finally, the particles around the vertical rotor fall down to the bottom. The parameters that would be related to the dry coating phenomena such as number of collision and average rotational distance are shown in Figure 14. Number of collision increases with an increase in the rotational speed. It increases rapidly up to $1000 \mathrm{rpm}$, however over $1000 \mathrm{rpm}$, it increases moderately. The rotational distance increases linearly with an increase in the rotational speed up to $2500 \mathrm{rpm}$. Over $3000 \mathrm{rpm}$, it decreases a little. That is because at high rotational speed, too many particles go up to the upper side of the vessel, and then the particles interrupt other particles motion each other. Those results indicate that the dry coating effect becomes lager along with the rotational speeds. On the other hand, the efficiency could be down. Figure 15 shows that the distribution of the colliding forces of the particles. The 
orders of forces range from $10^{-2}$ to $10^{2}$. The peak of the distribution increases with an increase in the rotational speed. In the same time, the forces at the peak increase too. This result indicates that the colliding forces increase with an increase in the rotational speed. However the rate is not as same rapidity as the initial rotational speed. In addition, if the yield stress of the particles is given, it is able to predict if the breakage of the particles happen or not by this approach.

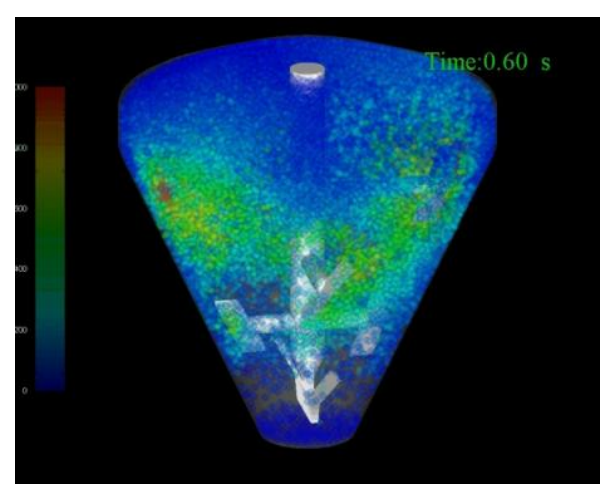

Figure 13. An example of snapshot of the DEM simulation at 1500rpm.

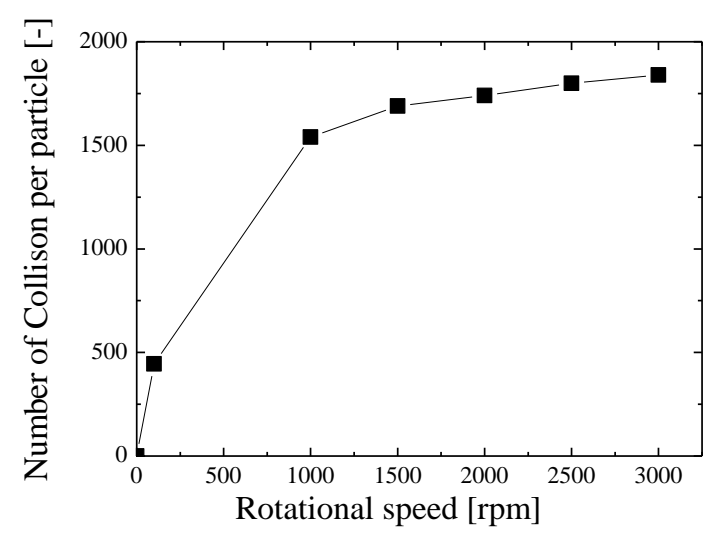

(a)

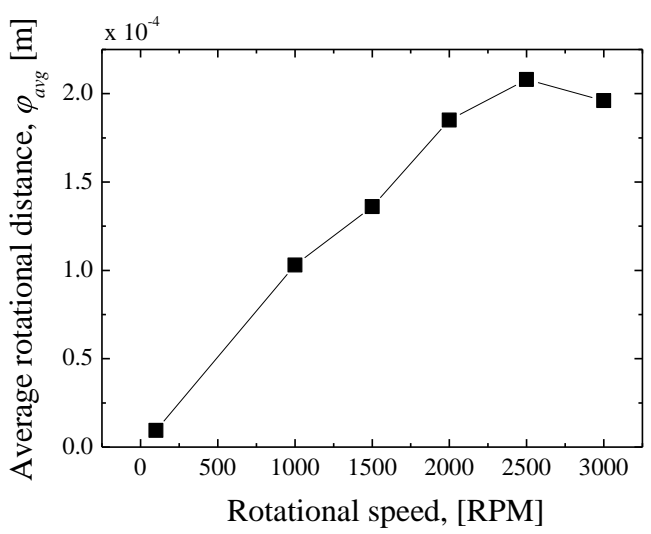

(b)

Figure 14. Numerical results (a) collision number, (b) rotational distance at each rotational speed.

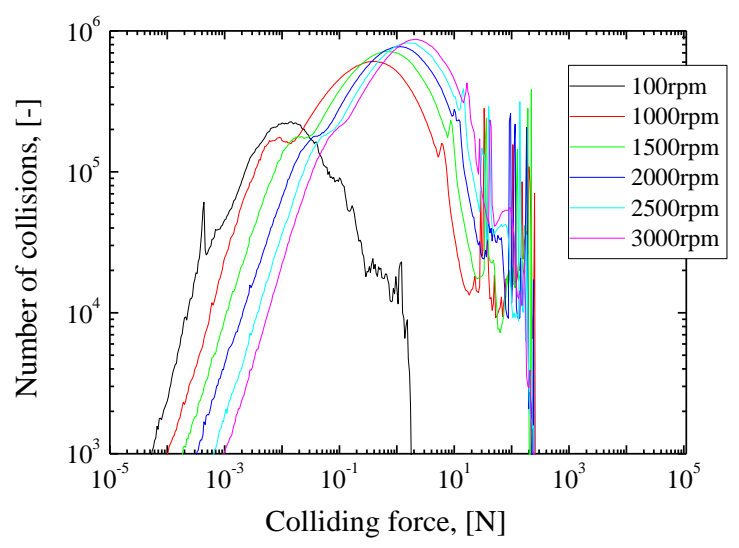

Figure 15. The distribution of the colliding forces of the particles. 


\section{CONCLUSION}

In this study, dry coating experiments were carried out by using a Cyclomix high shear mixer for the purpose of coating Suglets by MgSt using different operating conditions. SEM images of particle surface show that the invited particles initially cover the host particles and then they deform to appear the film-like shape coating. In addition, giving an excessive treatment to the particles should induce attrition, which makes the dry coating performance worse. The flowability becomes better along with the operation. However it gets worse when breakage or abrasion of host particles occurs. Particle size distribution indicates the presence of the separation of the invited particles and breakage of the host particles. The DEM simulation of these experiments has been performed. The results show that the dry coating performance becomes better along the rotational speed until an asymptotic level.

\section{LIST OF SYMBOLS}

\begin{tabular}{|c|c|c|}
\hline$C_{2 \mathrm{D}}$ & Packing fraction & {$[-]$} \\
\hline$D_{50}$ & Median diameter & {$[\mathrm{m}]$} \\
\hline$E$ & Young's modulus & {$[\mathrm{GPa}]$} \\
\hline$i$ & $i$-th particle & {$[-]$} \\
\hline$K_{\mathrm{H}}$ & Size ratio of both host and invited particles & {$[-]$} \\
\hline$N$ & Number of particles & {$[-]$} \\
\hline$R_{\mathrm{H}}$ & Radius of host particle & {$[\mathrm{m}]$} \\
\hline$R_{\mathrm{I}}$ & Radius of invited particle & {$[\mathrm{m}]$} \\
\hline$S_{\mathrm{H}}$ & Surface fraction on host particle & {$[-]$} \\
\hline$T$ & Total simulation time & {$[\mathrm{s}]$} \\
\hline$w$ & Mass ratio of invited and host powders & {$[-]$} \\
\hline$\theta_{\mathrm{H}}$ & Contact angle of host powder & {$\left[{ }^{\circ}\right]$} \\
\hline$\theta_{\mathrm{I}}$ & Contact angle of invited powder & {$\left[{ }^{\circ}\right]$} \\
\hline$\theta\left(t_{0}\right)$ & Contact angle at initial point & {$\left[{ }^{\circ}\right]$} \\
\hline$\rho_{\mathrm{H}}$ & Density of host particle & {$[\mathrm{kg} / \mathrm{m} 3]$} \\
\hline$\rho_{\mathrm{I}}$ & Density of invited particle & {$[\mathrm{kg} / \mathrm{m} 3]$} \\
\hline$\varphi_{\text {avg }}$ & Average rotational distance & {$[\mathrm{m}]$} \\
\hline$\varphi_{\mathrm{i}}$ & Rotational distance of $i$-th particle & {$[\mathrm{m}]$} \\
\hline$t$ & Timestep of the simulation & {$[\mathrm{s}]$} \\
\hline
\end{tabular}




\section{REFERENCES}

[1] Alonso M., Satoh M. , Myanami K., 1989, Mechanism of the combined coating-mechanofusion processing of powders, Powder Technology, 59, 42-52.

[2] Lefevre G., Galet. L., Chamayou A., 2010, Dry coating of talc particles with fumed silica: Influence of the silica concentration on the wettability and dispersibility of the composite particles, Power Technology, in press.

[3] Honda H., Kimura M., Honda F., Matsuno T., Koishi M., 1994, Preparation of monolayer particle coated powder by the dry impact blending process utilizing mechanochemical treatment, Colloids and Surfaces A: Physicochemical and Engineering Aspects, 82, 117-128.

[4] Watano S., Imada Y., Miyanami K., Wu C.Y., Dave R.N., Pfeffer R., Yoshida T., 2000, Surface modification of food fiber by dry particle coating, Journal of Chemical Engineering of Japan, 33, 848854.

[5] Ouabbas Y., Chamayou A., Galet L., Baron M., Thomas G., Grosseau P., Guilhot B., 2009, Surface modification of silica particles by dry coating: Characterization and powder ageing, Powder Technology, 190, 200-209.

[6] Lefevre G., Galet. L., Chamayou A., 2011, Dry Coating of Talc Particles: Effect of Material and Process Modifications on Their Wettability and Dispersibility, American Institute of Chemical Engineering, 57, 79-86.

[7] Iwasaki T., Satoh M., Ito T., 2002, Determination of optimum operating conditions based on energy requirement for particle coating in a dry process, 123, 105-113.

[8] Cundall P.A., Strack O.D.L., 1979, A discrete numerical model for granular assemblies, Geotechnique, 29, 47-65.

[9] Cleary P.W., Sawley M.L., 2002, DEM modelling of industrial granular flows: 3D case studies and the effect of particle shape on hopper discharge, Applied Mathematical Modelling, 26, 89-111.

[10] Kano J., Chujo N., Saito F., 1997, A method for simulating three dimensional motion of balls under presence of powder in a tumbling mill, Advanced powder technology, 8, 39-51.

[11] Matchett A.J., Yanagida T., Okudaira Y., Kobayashi S., 2000, Vibrating powder beds: a comparison of experimental and Distinct Element method simulated data, Powder Technology, 107, 1330 .

[12] Ouabbas Y., Dodds J., Galet L., Chamayou A., Baron M., 2009, Particle-particle coating in a cyclomix impact mixer, Powder Technology, 189, 245-252.

[13] Thomas G., Ouabbas Y., Grosseau P., Baron M., Chamayou A., Galet L., 2009, Modeling the mean interaction forces between powder particles. Application to silica gel-magnesium stearate mixtures, J. Applied Science, 255, 7500-7507. 